\title{
Does hybrid fixation prevent junctional disease after posterior fusion for degenerative lumbar disorders? A minimum 5-year follow-up study
}

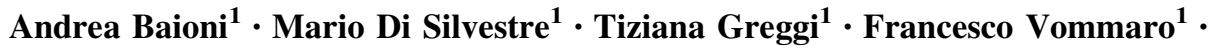 \\ Francesco Lolli ${ }^{1}$ Antonio Scarale ${ }^{1}$
}

Received: 16 September 2015/Revised: 28 September 2015/Accepted: 28 September 2015/Published online: 13 October 2015 (C) The Author(s) 2015. This article is published with open access at Springerlink.com

\begin{abstract}
Purpose Medium- to long-term retrospective evaluation of clinical and radiographic outcome in the treatment of degenerative lumbar diseases with hybrid posterior fixation. Methods Thirty patients were included with the mean age of 47.8 years (range 35 to 60 years). All patients underwent posterior lumbar instrumentation using hybrid fixation for lumbar stenosis with instability (13 cases), degenerative spondylolisthesis Meyerding grade I (6 cases), degenerative disc disease of one or more adjacent levels in six cases and mild lumbar degenerative scoliosis in five patients. Clinical outcomes were evaluated using Oswestry disability index (ODI), Roland and Morris disability questionnaire (RMDQ), and the visual analog scale (VAS) pain scores. All patients were assessed by preoperative, postoperative and follow-up standing plain radiographs and lateral $\mathrm{X}$-rays with flexion and extension. Adjacent disc degeneration was also evaluated by magnetic resonance imaging (MRI) at follow-up.
\end{abstract}

Andrea Baioni

andribaioni@hotmail.it

Mario Di Silvestre

mario.disilvestre@ior.it

Tiziana Greggi

tiziana.greggi@ior.it

Francesco Vommaro

francesco.vommaro@ior.it

Francesco Lolli

francesco.lolli@fastwebnet.it

Antonio Scarale

antonio.scarale@hotmail.com

1 Spine Surgery Department, Rizzoli Orthopaedic Institute, Via C.G. Pupilli 1, 40136 Bologna, BO, Italy
Results At a mean follow-up of 6.1 years, we observed on X-rays and/or MRI 3 cases of adjacent segment disease $(10.0 \%)$ : two of them $(6.6 \%)$ presented symptoms and recurred a new surgery. The last patient $(3.3 \%)$ developed asymptomatic retrolisthesis of L3 not requiring revision surgery. The mean preoperative ODI score was 67.6, RMDQ score was 15.1, VAS back pain score was 9.5, and VAS leg pain score was 8.6. Postoperatively, these values improved to 28.1, 5.4, 3.1, and 2.9, respectively, and remained substantially unchanged at the final follow-up: (27.7, 5.2, 2.9, and 2.7, respectively).

Conclusions After 5-year follow-up, hybrid posterior lumbar fixation presented satisfying clinical outcomes in the treatment of degenerative disease.

Keywords Hybrid posterior fixation - Adjacent segment disease $\cdot$ Degenerative lumbar disease

\section{Introduction}

Over the past decades, spinal fusion with instrumentation has become a common technique in the surgical treatment of symptomatic degenerative diseases of the lumbar spine. Technological advances such as transpedicular instrumentation have resulted in increased fusion rates, while decreasing the need for postoperative immobilization and brace therapy, and have increased the number of spinal fusions performed each year [1]. However, successful fusion has not always been accompanied by clinical improvement [2]. This apparent lack of correlation between surgical and clinical outcomes raises important questions about secondary, delayed phenomena that could adversely affect the final clinical outcome. 
Achievement of fusion may, in fact, have long-term effects on the immediately adjacent motion segments [3, 4]. At the junction with adjacent mobile segments, the rigidity of the fused segments induces increased constraints that can constitute a clinical concern [5-7]. The primary junctional complications can be facet degeneration, ligament hypertrophy, disc degeneration, and spinal stenosis $[5,8]$. This adjacent level degeneration is typically seen rostral to a fused segment, but may also occur caudal to a fusion, especially when it is performed at the L4-L5 level. The phenomenon is thought to be due to the altered biomechanics of the fused spine, wherein abnormal forces acting upon the intervertebral discs and facet joints adjacent to the fused segment precipitate the accelerated failure of these stabilizing elements [9]. From this evidence for adjacent segment degeneration emerged the concept of "dynamic" or "non fusion" stabilization of the lumbar spine.

Posterior dynamic stabilization, in which pedicle screw fixation is coupled with a flexible longitudinal connecting system, presumably could allow for the normalization of intersegmental motion [10-12]. This stands in contrast to traditional fusion surgery, in which the goal is complete and immediate elimination of motion and, ultimately, arthrodesis.

Recently available are hybrid systems, in which dynamic stabilization may be associated with a rigid fixation and a fusion. These systems are intended for use in patients in whom fusion is desired to treat severe instability or advanced degeneration at one or more levels, and in whom one or more adjacent segments exhibit degenerative changes (that are thought to be contributing to the patient's symptoms but are not of a severe-enough degree to warrant arthrodesis). So the unstable degenerative segments are instrumented with the static fixator and the adjacent segments are protected by the dynamic fixator [13]. From a biomechanical viewpoint, mobility of the transition disc can be preserved to some extent and thus the mechanical load can be partially shared by the dynamic fixator $[14,15]$.

However, at least two problems are inherent to hybrid fixation. First, whether hybrid fixators simply transfer the junctional constraints to the next adjacent segments. Second, which degenerative grade of the transition disc indicates use of a hybrid fixator. To the authors' knowledge, no follow-up study has previously been dedicated to the detailed investigation of these two questions $[14,16]$. The aim of this study is medium- to long-term retrospective evaluation of clinical and radiographic outcome in the treatment of degenerative lumbar diseases with hybrid posterior fixation. The series was limited to patients who received the same hybrid system. All patients were at a minimum 5-year follow-up.

\section{Materials and methods}

A retrospective database review was performed to identify all patients affected by degenerative lumbar disease, who underwent posterior lumbar instrumentation using hybrid fixation with the Dynesys transition option (DTO) in our department between 2006 and 2009.

Inclusion criteria were: (1) minimum age at surgery of 35 years and maximum of 60 years; (2) degenerative lumbar disease (stenosis with instability, degenerative spondylolisthesis, degenerative disc disease (DDD), or degenerative lumbar scoliosis) [17, 18]; (3) no previous lumbar surgery; (4) the same hybrid system (DTO); (5) proximal instrumented level not exceeding L1 and (6) minimum 5-year follow-up.

An independent spine surgeon reviewed all the selected patients' medical records and X-rays. Inpatient and outpatient charts were used for collecting demographic data, preoperative data (location of pain and symptoms), perioperative data (blood loss, surgical duration, hospital stay, and any medical- or surgery-related complications), and postoperative data, including revision surgeries. Clinical outcome was assessed by means of the Oswestry disability index (ODI), Roland-Morris disability questionnaire (RMDQ), and separate visual analog scale (VAS) scores for back and leg pain, completed by patients preoperatively, in the early postoperative period, and at the last follow-up.

Radiographic evaluation included preoperative, postoperative, and last follow-up standing plain radiographs and MRI before surgery and at last follow-up and was analyzed with particular attention paid to degeneration of the adjacent levels after hybrid fixation. Degenerative changes at the adjacent segments were considered to exist when there were at least two of the following criteria: (1) on standing $\mathrm{X}$-rays, the height of the adjacent disc reduced more than $70 \%$; (2) displacement more than $3 \mathrm{~mm}$ on the X-ray of the sagittal plane of the closest upper or lower segment; (3) segmental instability of more than $15^{\circ}$ on the lateral X-rays in flexion and extension [3, 19]; (4) segmental stenosis and/ or disc degeneration (grade III according Pfirmann classification [20]) at adjacent level on the follow-up MRI. Overall lumbar measures from the radiographs included lumbar lordosis (L1-L5), pelvic incidence (PI), pelvic tilt (PT) and sacral slope (SS).

The results were analyzed using $t$ test. Results are expressed as the mean (range), with a $p$ value $<0.05$ considered as being statistically significant.

\section{Preoperative patient data}

Thirty patients were included in the study. There were 18 women $(60 \%)$ and 12 men $(40 \%)$, with a mean age of 
47.8 years (range 35-60 years). All 30 patients had a degenerative lumbar disease. Thirteen of them $(43.3 \%)$ had a lumbar stenosis with instability of one or more lumbar levels (associated in 1 case with DDD of L5-S1). Six patients $(20 \%)$ had degenerative spondylolisthesis of grade 1 in the Meyerding classification, affecting L4-L5 in 3 cases and L5-S1 in 3 cases, associated in 4 patients with DDD of 1 level in 3 cases (L4-L5), 3 levels in 1 case (L3S1) and in 1 case with a lumbar stenosis. Six patients (20\%) had DDD affecting 1 level in 2 cases (L4-L5, L5S1) and 2 levels in 4 cases (L1-L3 in 1 case, L4-S1 in 3 cases). Five patients (16.7\%) had mild degenerative lumbar scoliosis associated in 1 patient with lumbar stenosis and in 1 case with DDD of L5-S1. Sixteen patients $(53.3 \%)$ had undergone a previous spine surgery but none a fusion or an instrumentation. At the time of surgery, 26 $(86.6 \%)$ patients reported low back pain and unilateral or bilateral leg pain (sciatica, crural pain, gluteal pain), 4 $(13.3 \%)$ patients reported only low back pain and 2 (6.7 \%) patients reported only leg pain; 4 (13.3\%) patients also had neurogenic claudication. All patients had failed to respond to conservative treatment conducted for at least 12 months. There were 0.5 comorbidities per patient, including arterial hypertension in 6 , arthritis in 1 , psoriasis in 1 , vertigo in 1 , B-hepatitis in 1 , renal lithiasis in 1 , mitral prolapse in 1 , hyperthyroidism in 1 , osteoporosis in 1 , and diabetes mellitus in 1 (Table 1).

\section{Surgical treatment}

All surgeries were performed by one experienced spine surgeon of our Department. Antibiotics were routinely started at the time of anesthesia induction and continued for an average of 9 days (range 8-11 days). The patients were

Table 1 Population

\begin{tabular}{lc}
\hline & Value \\
\hline Preoperative data & \\
Mean age & 51.2 \\
Women & 18 \\
Men & 12 \\
Stenosis with instability & 13 \\
Spondylolisthesis grade 1 & 6 \\
Degenerative disc disease (DDD) & 6 \\
Degenerative de novo lumbar scoliosis & 5 \\
Previous spine surgery & 16 \\
Back pain and leg pain & 24 \\
Back pain & 4 \\
Leg pain & 2 \\
Neurogenic claudication & 4 \\
Comorbidities per patient & 0.5 \\
\hline
\end{tabular}

treated under general anesthesia in the prone position. Stenosis was treated by laminectomy: the decompression was extended to the lateral recess, and foraminotomy was performed without interrupting the isthmus.

The DTO implant combines the Dynesys Neutralization System and the Optima Spinal System. The Dynesys (Zimmer) system was always placed cranially to the Optima system.

The DTO implant is made of a combined $100 \mathrm{~mm}$ polyethylene-terephthalate Dynesys cord and standard titanium $6 \mathrm{~mm}$ rod. Dynesys implants were used for dynamic fixation [18].

Dynesys implants consist of titanium alloy pedicle screws, polyethylene-terephthalate cords, and polycarbonate urethane spacers, which fit between the pedicle screw heads. The pedicle screws used in lumbar vertebrae were $7.2 \mathrm{~mm}$ in diameter and 40 or $45 \mathrm{~mm}$ in length. The pedicle entry point was lateral at the base of the transverse process. The screws were inserted as deep as possible. So as not to compromise the bone purchase of the screws, given their conical core, we avoided removing and reinserting them in the same hole. Each polycarbonate urethane spacer was cut to the desired length and threaded with a polyester cord, which was stretched between and fixed to two adjacent screw heads.

Optima implants were used for rigid fixation. Optima implants consist of titanium alloy pedicle screws. The pedicle screws used in lumbar vertebrae were $7.0 \mathrm{~mm}$ in diameter and 40 or $45 \mathrm{~mm}$ in length. The pedicle screws used in the sacrum were $7.0 \mathrm{~mm}$ in diameter and $40 \mathrm{~mm}$ in length. Between Dynesys pedicle screws and Optima pedicle screws, there were the polyaxial Optima Transition screws.

Iliac screws were not used in anyone of the patients. No circumferential lumbosacral fusion was performed in these patients. Allograft bank bone (one femur head for every patient) and autograft bone (spinous processes and laminae obtained from decompression procedure) were used in all 30 patients at fusion levels. Redon drains were applied and maintained for a mean of 3.9 days (range 3-4 days).

\section{Perioperative data}

All 30 patients had hybrid fixation with DTO implants: two levels were treated in 14 patients (46.7 \%): L3-L5 in 3 and L4-S1 in 11; three levels were treated in 4 patients (13.3\%): L2-L5 in 1 and L3-S1 in 3; four levels were treated in 4 patients (13.3\%): L1-L5 in 1 and L2-S1 in 3; and five levels were treated in 8 patients $(26.7 \%)$ : L1-S1 (Table 2).

In 21 patients $(70 \%)$, the stabilization was combined with decompressive laminectomy of one level in 11 patients (36.7 \%): L2-L3 in 1, L3-L4 in 1, L4-L5 in 4, and 
Table 2 Levels of instrumentation

\begin{tabular}{llllc}
\hline Level & Dynamic & Rigid & Number & Percent $\%$ \\
\hline \multicolumn{2}{l}{ Instrumented levels } & & & \\
L1-L5 & L1-L3 & L3-L5 & 1 & 2.7 \\
L1-S1 & L1-L3 & L3-S1 & 1 & 2.7 \\
L1-S1 & L1-L4 & L4-S1 & 3 & 8.1 \\
L1-S1 & L1-L5 & L5-S1 & 4 & 10.8 \\
L2-L5 & L2-L4 & L4-L5 & 1 & 2.7 \\
L2-S1 & L2-L4 & L4-S1 & 1 & 2.7 \\
L2-S1 & L2-L5 & L5-S1 & 2 & 5.4 \\
L3-L5 & L3-L4 & L4-L5 & 3 & 8.1 \\
L3-S1 & L3-L4 & L4-S1 & 2 & 5.4 \\
L3-S1 & L3-L5 & L5-S1 & 1 & 2.7 \\
L4-S1 & L4-L5 & L5-S1 & 11 & 29.7 \\
\hline
\end{tabular}

Table 3 Laminectomy levels

\begin{tabular}{llc}
\hline Level & Number & Percent \% \\
\hline Laminectomy & & \\
1 level & & \\
L2-L3 & 1 & 3.3 \\
L3-L4 & 1 & 3.3 \\
L4-L5 & 4 & 13.3 \\
L5-S1 & 5 & 16.7 \\
2 levels & & \\
L3-L5 & 3 & 10.0 \\
L4-S1 & 2 & 6.7 \\
3 levels & & \\
L3-S1 & 3 & 6.7 \\
4 levels & & \\
L2-S1 & 2 & \\
\hline
\end{tabular}

L5-S1 in 5, of two levels in 5 patients (16.7 \%): L3-L5 in 3 , L4-S1 in 2, of three levels in 3 patients (10\%): L3-S1, and of four levels in 2 patients (6\%): L2-S1 (Table 3).

Mean operating time was $130 \mathrm{~min}$ (range 10-160 min), mean hospital stay was 5.9 days (range 4-8 days), and mean blood loss was $950 \mathrm{cc}$ (range 200-1.600 cc). Patients were returned to the upright position 1.6 days postoperatively (range $2-3$ days) with a lumbar orthosis, which was prescribed for 1 month.

\section{Results}

\section{Clinical outcome}

The mean preoperative ODI score was $67.6 \%$ (range 56-90), mean postoperative score was 28.1 (range 0-66), and the final follow-up score was 27.7 (range 0-80) $(p<0.05)$, with a mean final improvement of $59.0 \%$ (range $12-100 \%)(p<0.05)$.

The mean preoperative RMDQ score was 15.1 of 24 (range 8-21), mean postoperative score was 5.4 (range $0-18$ ), and the final follow-up score was 5.2 (range 0-17) $(p<0.05)$, with a mean final improvement of $65.6 \%$ (range $9.1-100 \%)(p<0.05)$.

The mean leg pain VAS decreased from a preoperative score of 8.6 of 10 (range 2-10) to a mean postoperative score of 2.9 (range $0-7$ ) and 2.7 (range $0-10$ ) at the last follow-up $(p<0.05)$, with a mean final improvement of $59.6 \%$ (range $10-96.4 \%)(p<0.05)$.

The mean back pain VAS decreased from a preoperative score of 9.5 (range 8-10) to a postoperative score of 3.1 (range 0-8) and 2.9 (range 0-10) at the last follow-up $(p<0.05)$, with a mean final improvement of $63.1 \%$ (range 20-97.0\%) $(p<0.05)($ Table 4$)$.

\section{Radiologic outcome}

The mean lumbar lordosis was $-40.8^{\circ}$ (range $-8.8^{\circ}$ to $-67.3^{\circ}$ ) before surgery, $-38.1^{\circ}$ (range $-17.7^{\circ}$ to $-60.1^{\circ}$ ) after surgery, and $-35.4^{\circ}$ (range $-21.0^{\circ}$ to $-58.0^{\circ}$ ) at the last follow-up $(p<0.05)$.

Pelvic incidence was $55.5^{\circ}$ (range $29.6^{\circ}$ to $81.1^{\circ}$ ) before surgery, $55.6^{\circ}$ (range $30.4^{\circ}$ to $86.3^{\circ}$ ) after surgery, and $51.4^{\circ}$ (range $30.2^{\circ}$ to $68.0^{\circ}$ ) at the last follow-up $(p<0.05)$.

Pelvic tilt was $20.0^{\circ}$ (range $2.7^{\circ}$ to $39.5^{\circ}$ ) before surgery, $21.5^{\circ}$ (range $5.5^{\circ}$ to $35.3^{\circ}$ ) after surgery, and $21.3^{\circ}$ (range $7.3^{\circ}$ to $\left.31.0^{\circ}\right)$ at the last follow-up $(p<0.05)$ (Figs. 1, 2).

Sacral slope was $36.3^{\circ}$ (range $7.2^{\circ}$ to $52.3^{\circ}$ ) before surgery, $34.3^{\circ}$ (range $22.2^{\circ}$ to $52.8^{\circ}$ ) after surgery, and $31.0^{\circ}$ (range $20.1^{\circ}$ to $39.0^{\circ}$ ) at the last follow-up $(p<0.05$ ) (Table 5).

Table 4 Clinical outcome

\begin{tabular}{lccclc}
\hline & Preoperative & Postoperative & Follow-up & Final improvement $(\%)$ & $p$ \\
\hline \multicolumn{2}{l}{ Clinical outcome } & & & & \\
ODI & $67.6(56-90)$ & $28.1(0-66)$ & $27.7(0-80)$ & $59.0(12-100)$ & $<0.05$ \\
RMDQ & $15.1(8-21)$ & $5.4(0-18)$ & $5.2(0-18)$ & $65.6(9.1-100)$ & $<0.05$ \\
VAS back & $9.5(8-10)$ & $3.1(0-8)$ & $2.9(0-10)$ & $63.1(20-97)$ & $<0.05$ \\
VAS leg & $8.6(2-10)$ & $2.9(0-7)$ & $2.7(0-10)$ & $59.6(10-96.4)$ & $<0.05$ \\
\hline
\end{tabular}



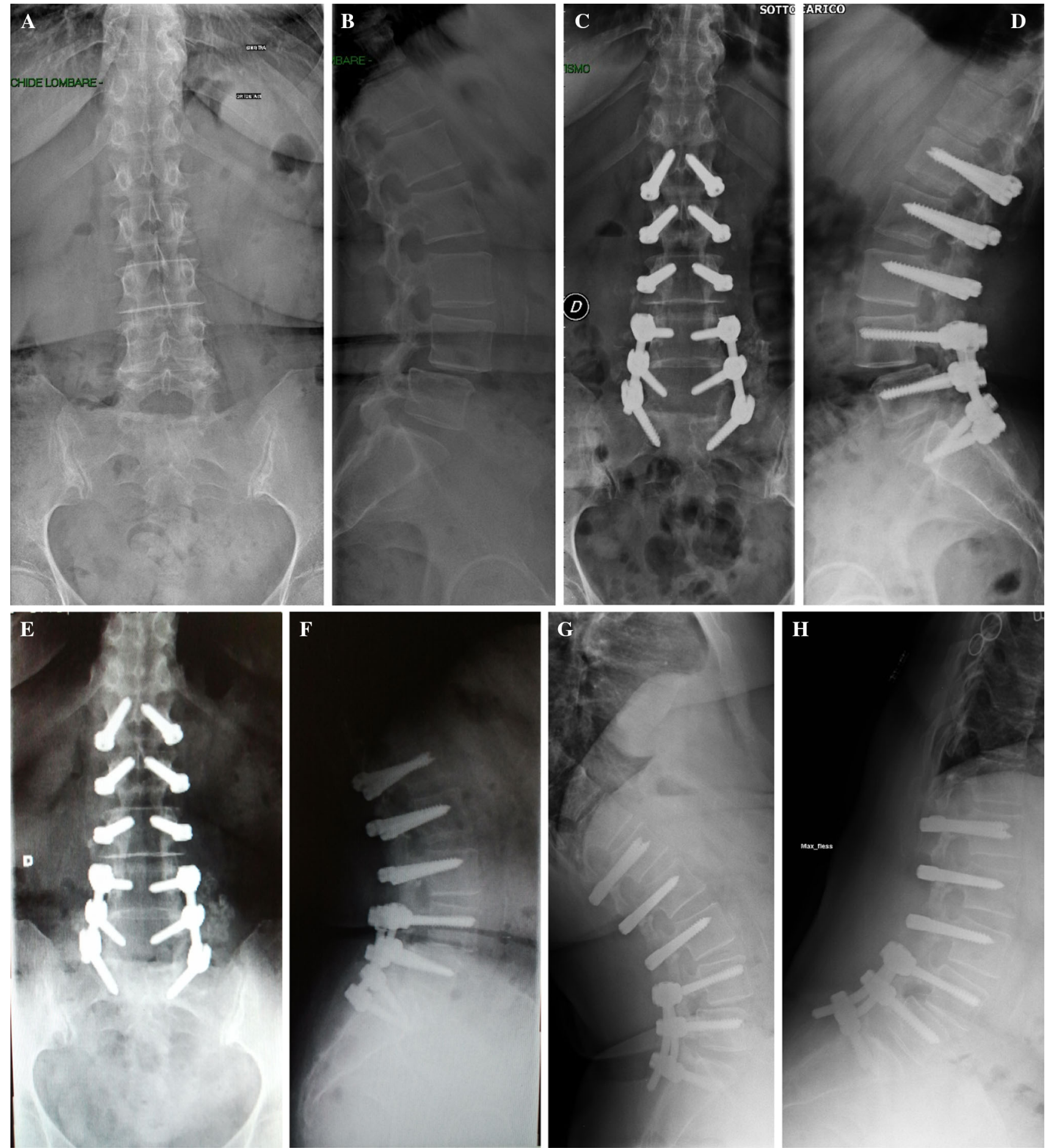

Fig. 1 a, b Case 15: female, 60 years old. De novo mild lumbar scoliosis and spondilolysthesis at L4-L5; c, d treatment: L1-L4 dynamic and L4-L5 rigid fixation, L2-L5 laminectomy; $\mathbf{e}-\mathbf{h}$ no adjacent degenerative changes at 6.5-year follow-up (standard and flexion-extension X-rays)

\section{Degenerative changes at adjacent segments}

Degenerative changes at adjacent segments were observed in 3 patients $(10.0 \%)$, whose mean age at index operation was 55.0 (range 50 to 62) years (Table 6). Two of them presented symptoms, whereas the other one was asymptomatic. Two cases only received new surgery. The change occurred at the upper segments in two cases treated with an L4-S1 hybrid instrumentation while in the other patient with L2-L5 fixation had changes at both the upper and 

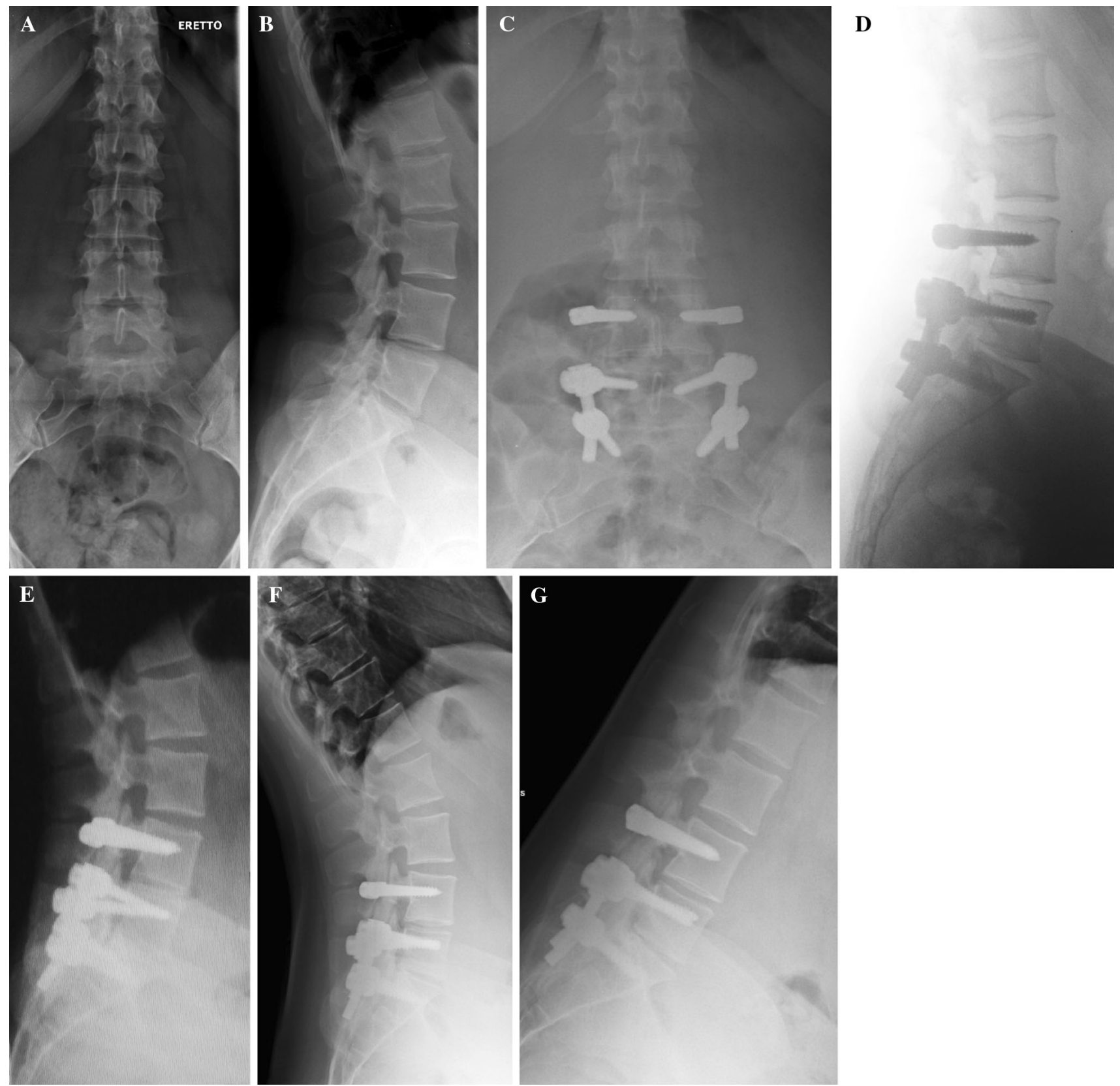

Fig. 2 a, b Case 21: male, 39 years old, DDD at L4-L5 and L5-S1; c, d treatment: L4-L5 dynamic and L5-S1 rigid fixation, L4-L5 laminectomy; e, f no adjacent degenerative changes at 7.1-year follow-up

Table 5 Radiologic outcome

\begin{tabular}{lccc}
\hline & Preoperative & Postoperative & Follow-up \\
\hline Radiologic outcome & & & \\
Lumbar lordosis (LL) & $-40.8^{\circ}\left(-8.8^{\circ} /-67.3^{\circ}\right)$ & $-38.1^{\circ}\left(-17.7^{\circ} /-60.1^{\circ}\right)$ & $-35.4^{\circ}\left(-21^{\circ} /-58^{\circ}\right)$ \\
Pelvic incidence (PI) & $55.6^{\circ}\left(29.6^{\circ} / 81.1^{\circ}\right)$ & $55.6^{\circ}\left(29.6^{\circ} / 81.1^{\circ}\right)$ & $55.6^{\circ}\left(29.6^{\circ} / 81.1^{\circ}\right)$ \\
Pelvic tilt (PT) & $20.0^{\circ}\left(2.7^{\circ} / 39.5^{\circ}\right)$ & $21.5^{\circ}\left(5.5^{\circ} / 39.3^{\circ}\right)$ & $21.3^{\circ}\left(7.3^{\circ} / 31^{\circ}\right)$ \\
Sacral slope (SS) & $35.6^{\circ}\left(7.2^{\circ} / 52.3^{\circ}\right)$ & $34.1^{\circ}\left(22.2^{\circ} / 52.8^{\circ}\right)$ & $34.3^{\circ}\left(20.1^{\circ} / 39.0^{\circ}\right)$ \\
\hline
\end{tabular}


Table 6 Degenerative changes at adjacent segments

\begin{tabular}{|c|c|c|c|}
\hline & Case 5 & Case 7 & Case 12 \\
\hline \multicolumn{4}{|c|}{ Degenerative changes at adjacent segments. } \\
\hline Age at surgery & 53 years & 52 years & 60 years \\
\hline Clinic pre-op & Back pain, left sciatica & Back pain, bilateral sciatica & Bilateral sciatica \\
\hline $\begin{array}{l}\text { Pre-op } \\
\text { diagnosis }\end{array}$ & DDD at L2-L3, L3-L4, L4-L5 & $\begin{array}{l}\text { Spondilolysthesis } \mathrm{I}^{\circ} \text { Meyerding of L5-S1, } \\
\text { DDD at L4-L5 }\end{array}$ & $\begin{array}{l}\text { Stenosis with } \\
\text { instability }\end{array}$ \\
\hline First surgery & L2-L5 (L2-L4 dynamic, L4-L5 rigid) & L4-S1 (L4-L5 dynamic, L5-S1 rigid) & $\begin{array}{l}\text { L4-S1 (L4-L5 } \\
\text { dynamic, L5-S1 } \\
\text { rigid) }\end{array}$ \\
\hline $\begin{array}{l}\text { Post-op } \\
\text { degenerative } \\
\text { changes }\end{array}$ & DDD at T12-L1, L1-L2, L5-S1 & DDD and stenosis at L3-L4 & retrolisthesis of L3 \\
\hline $\begin{array}{l}\text { Months after } \\
\text { first surgery }\end{array}$ & 31 & 34 & 60 \\
\hline Symptoms & Back pain, left cruralgia & Back pain, bilateral cruralgia & Asymptomatic \\
\hline $\begin{array}{r}\text { Revision } \\
\text { surgery }\end{array}$ & $\begin{array}{l}\text { Extension of dynamic fixation from } \mathrm{L} 2 \text { to } \mathrm{T} 12 \text { and } \\
\text { extension of the fusion from L5 to } \mathrm{S} 1\end{array}$ & $\begin{array}{l}\text { Extension to L3 of hybrid fixation and } \\
\text { laminectomy of L3 (hybrid L3-S1) }\end{array}$ & No \\
\hline $\begin{array}{l}\text { Result at } \\
\text { follow-up }\end{array}$ & No symptoms & No symptoms & Asymptomatic \\
\hline
\end{tabular}

lower segments. Thirty-one months after surgery, one patient (case 5) developed persistent crural pain resistant to medication without neurologic deficit, attributed to disc degeneration (grade 3 according to Pfirrmann's classification) at the lower and at the upper junctional levels. In this patient, revision surgery was performed 41 months after the index operation, with extension of dynamic fixation from L2 to T12 and extension of the fusion from L5 to S1. Another patient (case 7) developed adjacent segment disease; he presented DDD and stenosis at L3-L4 above the index L4-S1 instrumentation with low back pain and bilateral cruralgia 34 months after surgery: the new surgery consisted in extension to L3 of the hybrid construct (dynamic L3-L4 and rigid L4-S1) with L3-L4 laminectomy (Fig. 3). The third patient (case 12), which involved asymptomatic retrolisthesis of L3 60 months after surgery, did not require revision surgery. At the last follow-up, the third patient was still asymptomatic.

No screw loosening or breakage was observed at the follow-up. No neurologic complication and no minor complication were observed in any of the 30 patients.

\section{Discussion}

The phenomenon of adjacent segment disease (ASD), referring to accelerated degenerative changes occurring at the extremities of a posterior fusion, has received increasing attention as ever more spinal fusions are performed and long-term follow-up data become available [3, 11]. While the evolution and prevalence of ASD are not fully known, there is increasing evidence in literature that its effects may be seen soon after fusion surgery and in as many as $30 \%$ of patients $[3,4]$. Cheh et al. reported a rate of clinical ASD of $30.3 \%$ and showed that patients in whom adjacent level disease developed had significantly worse Oswestry Disability Index scores than those without adjacent level disease. They further identified age $>50$ years at the time of surgery, increasing length of fusion, and extension of the fusion to L1-L3 as significant risk factors for the development of adjacent level disease. No significant difference was identified between posterior and circumferential fusion [3].

Over the past 20 years, an array of posterior pedicle fixation-based motion preservation systems has been introduced as many in the spine community have sought to decrease the incidence of ASD [21]. One of these systems, the dynamic neutralization system (Dynesys), has been in use at our Institute for the past twenty years [18]. The dynamic stabilization approach promises to do so in a more physiological manner. By "restoring" normal motion, mobility is theoretically preserved rather than eliminated, and the forces acting above and below the construct are altered to a lesser extent, reducing the potential undesirable effects of fusion. Compared with static fixation, numerous types of dynamic fixators have been developed to preserve the mobility of the transition segments and to reduce the occurrence of the junctional problem [21-23]. Among them, the dynamic neutralization system (Dynesys) is one of the commonly used dynamic fixators [12, 24]. The Dynesys system consists of titanium alloy pedicle screws, cannulated polycarbonate urethane (PCU) spacers, and tensioned cords made of polyethylene terephthalate (PET). Similar to static fixation, the Dynesys system uses pedicle 

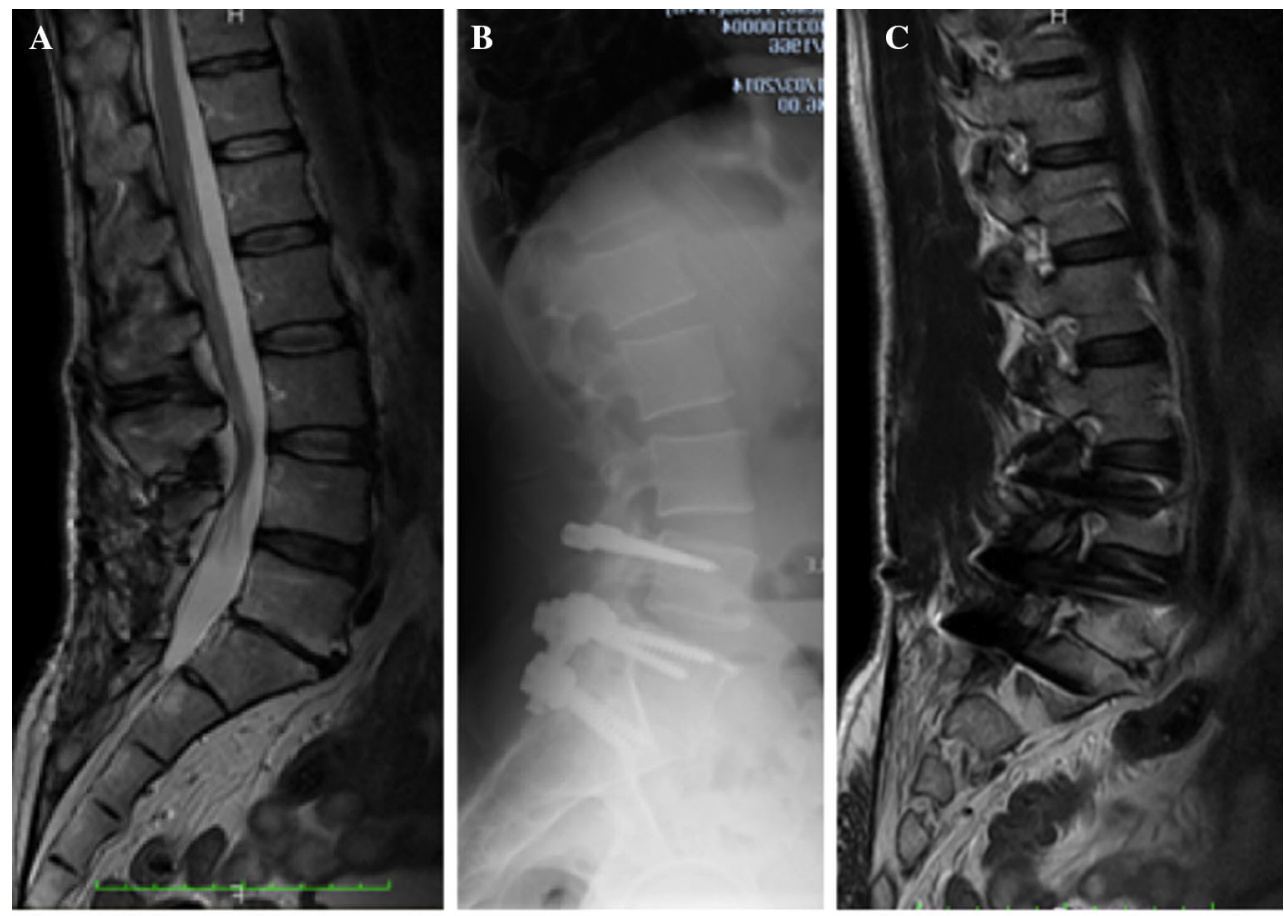

D
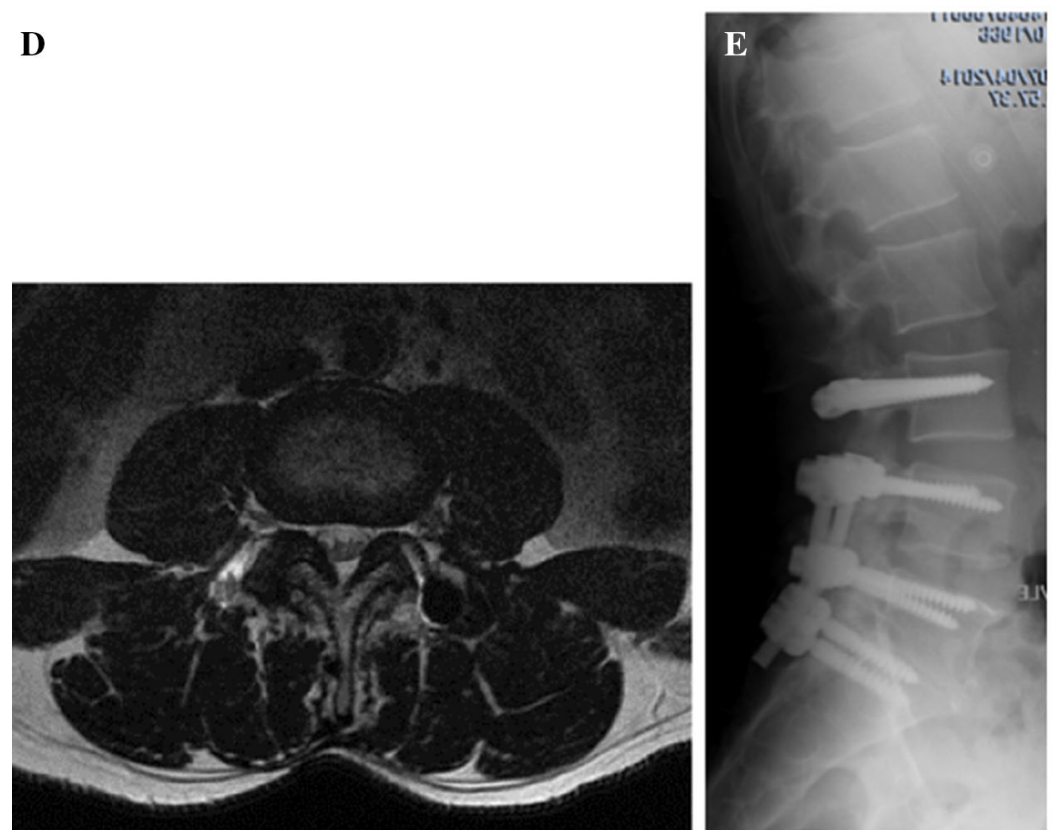

Fig. 3 a Case 7: male, 52 years old. Preoperative MRI: severe DDD at L5-S1 and DDD at L4-L5; b treatment: L4-L5 dynamic and L5S1 rigid fixation; c, d MRI 34 months after surgery: stenosis and

screws for anchorage in the vertebral bodies via the pedicles. Subsequently, the flexible cords in spacers of adequate length are extended between and connected to the screw heads.

More recently, the use of hybrid systems has spread in the treatment of the patient in whom decompression and fusion are required at one or more levels, but in whom there is also the potential for symptomatic degenerative
DDD at L3-L4; e new surgery: extension to L3 of hybrid construct and laminectomy of L3

changes at one or more adjacent levels. One of these is the DTO implant (Dynesys transition option), in which a Dynesys-like extension is added above Optima fusion instrumentation. Published studies about hybrid pedicle screw constructs are few, and long-term follow-up data are even more scarce. Maserati et al. reported that three $(12.0 \%)$ of their 24 patients developed symptomatic degenerative changes at or above the dynamically 
stabilized levels, but the mean follow-up was only 8 months [25].

We limited the present study to the DTO for homogeneity of the series and conduced consecutive cares with more than 5-year follow-up. However, the present series must be interpreted in the context of its limitations (the retrospective nature of the review and the fact that patients were not randomized).

In our study, evidence of radiographic ASD was noted in $3(10.0 \%)$ of the original 30 patients, an incidence similar to that in the preliminary report of Maserati et al. [25] but after much longer follow-up in our patients. The present incidence of $10 \%$ radiographic ASD was four times lower than the incidence of radiographic ASD reported during the first 5 years after fusion surgery by Cheh et al. [3], suggesting that hybrid fixation may indeed delay the development of ASD above lumbar fusion. Perhaps more importantly, the present incidence of symptomatic ASD $(6.7 \%)$ was also four times lower than the incidence of ASD after fusion alone (30\%) [3]. The clinical presentation was development of low back pain in both of our patients with cruralgia without neurological deficit who required additional surgery at adjacent levels (Table 6).

Unconscious patients who developed radiographic ASD were all over 50 years of age at time of index surgery. This finding was consistent with the conclusions of Cheh et al. who observed that patients older than 50 were at a higher risk of developing clinical ASD after instrumented fusion than those who were 50 or younger [3].

In two of our patients, degeneration of the adjacent segment occurred cranial to the proximal instrumented vertebra (PIV) and in one patient it occurred both cranial and caudal to the instrumented vertebrae. One reason that we did not observe ASD in the caudal segment was also because the last instrumented vertebra was S1 in 25 of our 30 patients. The three patients with ASD presented PIV at L4 in two cases while one patient had PIV in L2. In our series, the location of the PIV was not a significant factor for the development of ASD.

Finally, in our series, two patients who developed ASD had a high PI $\left(>60^{\circ}\right)$ or a moderate PI $\left(46^{\circ}<\right.$ PI $\left.<60^{\circ}\right)$ with insufficient lordosis correction. The third patient (case 12) had a low PI with an acceptable lordosis correction and he was asymptomatic (Table 7). Despite this, we did not observe mechanical complication [26].

Because we had no case of implant breakage or screw loosening, the present series supports the safety and reliability of the hybrid posterior fixation system. Clinical improvement, as measured by changes in ODI score, RMDQ score and VAS scores (both back and leg pain), was better in patients without radiographic ASD than in the three patients who developed ASD.
Table 7 Spinopelvic parameters in patients developed degenerative changes at adjacent segments

\begin{tabular}{llll}
\hline & Case 5 & Case 7 & Case 12 \\
\hline \multicolumn{2}{l}{ Spinopelvic parameters } & & \\
PI pre-op & 67.1 & 55.9 & 43.4 \\
PI post & 67.1 & 55.9 & 43.4 \\
PI f.u. & 67.1 & 55.9 & 43.4 \\
PT pre-op & 21.5 & 14.6 & 13.3 \\
PT post & 28.9 & 23.3 & 23.5 \\
PT f.u. & 27.7 & 20.0 & 23.5 \\
SS pre-op & 45.6 & 41.3 & 30.1 \\
SS post & 38.2 & 31.7 & 19.9 \\
SS f.u. & 39.4 & 35.9 & 19.9 \\
LL pre-op & 58.7 & 63.9 & 49.2 \\
LL post & 49.3 & 49.7 & 33.5 \\
LL f.u. & 49.3 & 54.6 & 33.5 \\
\hline
\end{tabular}

\section{Conclusions}

The hybrid posterior fixation system represents a technology that allows for the coupling of arthrodesis with dynamic stabilization at adjacent levels in the lumbar spine.

The prevalence of radiographic ASD in our study was $10.0 \%$ ( 3 of 30 ). Patients over the age of 50 could be at a higher risk of developing ASD than those who were 50 years old or younger. The number of instrumented segments was not a risk factor for the development of ASD in the lumbar degenerative spine. Because the observed clinical outcomes were good and there was no case of implant breakage or screw loosening, the present series supports the efficacy, safety and reliability of the hybrid posterior fixation system.

\section{Compliance with ethical standards}

\section{Conflict of interest None.}

Open Access This article is distributed under the terms of the Creative Commons Attribution 4.0 International License (http://crea tivecommons.org/licenses/by/4.0/), which permits unrestricted use, distribution, and reproduction in any medium, provided you give appropriate credit to the original author(s) and the source, provide a link to the Creative Commons license, and indicate if changes were made.

\section{References}

1. Weinstein JN, Lurie JD, Olson PR et al (2006) United States' trends and regional variations in lumbar spine surgery: 1992-2003. Spine (Phila Pa 1976) 31:2707-2714

2. Bono CM, Lee CK (2004) Critical analysis of trends in fusion for degenerative disc disease over the past 20 years: influence of technique on fusion rate and clinical outcome. Spine (Phila Pa 1976) 29:455-463 (discussion Z5) 
3. Cheh G, Bridwell KH, Lenke LG et al (2007) Adjacent segment disease following lumbar/thoracolumbar fusion with pedicle screw instrumentation: a minimum 5-year follow-up. Spine (Phila Pa 1976) 32:2253-2257

4. Chou WY, Hsu CJ, Chang WN et al (2002) Adjacent segment degeneration after lumbar spinal posterolateral fusion with instrumentation in elderly patients. Arch Orthop Trauma Surg 122:39-43

5. Chen WJ, Lai PL, Tai CL et al (2004) The effect of sagittal alignment on adjacent joint mobility after lumbar instrumentation-a biomechanical study of lumbar vertebrae in a porcine model. Clin Biomech (Bristol, Avon) 19:763-768

6. Heini PF (2010) Non rigid stabilization of the spine-problems observed: screw loosening/breakage/implant failure/adjacent segment degeneration. In Szpalski M, Gunzburg R, Rydevik BL et al (eds) Surgery for Low Back Pain. Springer, Heidelberg, pp 233-239

7. Hudson RS, Gee JE, Billys JB et al (2011) Hybrid dynamic stabilization with posterior spinal fusion in the lumbar spine. SAS Journal 5:36-43

8. Morishita Y, Ohta H, Naito M et al (2011) Kinematic evaluation of the adjacent segments after lumbar instrumented surgery: a comparison between rigid fusion and dynamic non-fusion stabilization. Eur Spine J 20:1480-1485

9. Lee CK, Langrana NA (1984) Lumbosacral spinal fusion. A biomechanical study. Spine (Phila Pa 1976) 9:574-581

10. Nockels RP (2005) Dynamic stabilization in the surgical management of painful lumbar spinal disorders. Spine (Phila Pa 1976) 30:S68-S72

11. Schmoelz W, Huber JF, Nydegger T et al (2003) Dynamic stabilization of the lumbar spine and its effects on adjacent segments: an in vitro experiment. J Spinal Disord Tech 16:418-423

12. Schnake KJ, Schaeren S, Jeanneret B (2006) Dynamic stabilization in addition to decompression for lumbar spinal stenosis with degenerative spondylolisthesis. Spine (Phila Pa 1976) 31:442-449

13. Schwarzenbach O, Rohrbach N, Berlemann U (2010) Segmentby-segment stabilization for degenerative disc disease: a hybrid technique. Eur Spine J 19:1010-1020

14. Galbusera F, Bellini CM, Anasetti F et al (2011) Rigid and flexible spinal stabilization devices: a biomechanical comparison. Med Eng Phys 33:490-496
15. Zander T, Rohlmann A, Burra NK et al (2006) Effect of a posterior dynamic implant adjacent to a rigid spinal fixator. Clin Biomech (Bristol, Avon) 21:767-774

16. Rohlmann A, Zander T, Bergmann G et al (2012) Optimal stiffness of a pedicle-screw-based motion preservation implant for the lumbar spine. Eur Spine J 21:666-673

17. Aebi M (2005) The adult scoliosis. Eur Spine J 14:925-948

18. Di Silvestre M, Lolli F, Bakaloudis G et al (2010) Dynamic stabilization for degenerative lumbar scoliosis in elderly patients. Spine 35(227):34

19. Soh J, Lee JC, Shin BJ (2013) Analysis of risk factors for adjacent segment degeneration occurring more than 5 years after fusion with pedicle screw fixation for degenerative lumbar spine. Asian Spine J 7:273-281

20. Pfirrmann CW, Metzdorf A, Zanetti M et al (2001) Magnetic resonance classification of lumbar intervertebral disc degeneration. Spine (Phila Pa 1976) 26:1873-1878

21. Bono CM, Kadaba M, Vaccaro AR (2009) Posterior pedicle fixation-based dynamic stabilization devices for the treatment of degenerative diseases of the lumbar spine. J Spinal Disord Tech 22:376-383

22. Barrey CY, Ponnappan RK, Song J et al (2008) Biomechanical evaluation of pedicle screw-based dynamic stabilization devices for the lumbar spine: a systematic review. SAS J 2:159-170

23. Sangiorgio SN, Sheikh H, Borkowski SL et al (2011) Comparison of three posterior dynamic stabilization devices. Spine (Phila Pa 1976) 36:E1251-E1258

24. Putzier M, Hoff E, Tohtz S et al (2010) Dynamic stabilization adjacent to single-level fusion: part II. No clinical benefit for asymptomatic, initially degenerated adjacent segments after 6 years follow-up. Eur Spine J 19:2181-2189

25. Maserati MB, Tormenti MJ, Panczykowski DM et al (2010) The use of a hybrid dynamic stabilization and fusion system in the lumbar spine: preliminary experience. Neurosurg Focus 28:E2

26. Le Huec JC, Cogniet A, Demezon H et al (2015) Insufficient restoration of lumbar lordosis and FBI index following pedicle subtraction osteotomy is an indicator of likely mechanical complication. Eur Spine J 24(Suppl 1):S112-S120 